I Universidade Federal de Minas Gerais (UFMG), Instituto de Estudos

Avançados Transdisciplinares (Ieat), Belo Horizonte, MG, Brasil

renanweil@gmail.com

https://orcid.org/oooo-000I-6I09-684I

Renan Springer de Freitas'

\title{
THE SOCIOLOGY OF KNOWLEDGE AND ITS MOVEMENTS
}

"The sociology of knowledge is alive and kicking" was the title given by Lewis Coser (1987) to his review of a collection of articles, published in I984, edited by Nico Stehr and Volker Meja (I984), whose contributions contained what was supposedly most relevant and innovative in the discipline at the time. In asserting that the sociology of knowledge was very much 'alive,' Coser was implying, of course, that there might be some reason for it not to be so. But what reason? He does not tell us, though he explains the title given to the review when he mentions that the discipline's "imminent death" had already been foretold various times. It remains unclear what these sombre predictions were based on, yet they are unsurprising when we recall that for at least 30 years the discipline had seen numerous attempts to 'redefine' its course. The first occurred in I 966 with the publication of The social construction of reality, the celebrated "treatise in the sociology of knowledge" by Peter Berger and Thomas Luckmann (I966). Five years later, Norbert Elias (I971a, b), no less, took the same route, publishing the article "Sociology of knowledge: new perspectives" in two instalments in the journal Sociology. Another five years passed and a new venture was made: this time it was the turn of the Edinburgh sociologist David Bloor (I976) to propose his "Strong programme in the sociology of knowledge". A short while later, in I984, the aforementioned collection of articles edited by Stehr and Meja was released, whose contributions, following the path cleared by Bloor's work, expressed - with some exceptions - an endeavour to 
redefine the courses of what had become known as the sociology of scientific knowledge. A decade or so later it would be the turn of the periodical Social Epistemology to dedicate a special issue to what it called "New directions in the

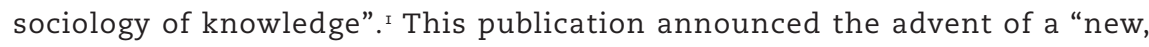
hermeneutically grounded sociology of knowledge" (Kögler, I997b: 223). Another two years passed and yet another endeavour appeared, presenting itself under the name of a hermeneutic sociology of knowledge (Hitzler, Reichertz \& Schröer, I999. Other attempts may have followed these, but I remain unaware of their existence, much less of their fate. Among all the cited endeavours, the only ones that effectively opened up a field of empirical investigation - on which I shall focus attention in section 2 - were the "Strong programme in the sociology of knowledge" and the sociology of scientific knowledge. As for the rest, I remain oblivious to what happened to the new perspectives announced in I97I, or the new directions announced in I997, or the hermeneutic sociology of knowledge announced in I999.

However, the sociology of knowledge does not exist solely as an academic discipline. Beyond the sociology of knowledge that became established as such following the seminal writings of Mannheim, published in the I920s, ${ }^{2}$ there is another one that never turned into a discipline, but nevertheless remains alive and kicking within other disciplines. In what we could call this 'intrauterine' condition, it prospers without the help of any endeavour to redefine its course. In this article I discuss the fertility of both the sociology of knowledge that established itself as an academic discipline and this sociology of knowledge that is alive and kicking in an intrauterine condition. This aim in mind, I have to explain what the distinctive mark common to both is.

This task is not difficult for anyone able to turn for assistance to Robert Merton (I968). In the chapter devoted to the sociology of knowledge in his celebrated Social theory and social structure, published for the first time in I949, Merton argued that this area of investigation could not exist without the "signal hypothesis" that the successful distinguishing of truth from error is as socially conditioned as it is conspicuously unsuccessful. ${ }^{3}$ The distinctive mark of any sociology of knowledge is none other than this "signal hypothesis". The aim here, therefore, is to show the different modes through which a sociology of knowledge can make itself present (can be alive and kicking) whenever our "signal hypothesis" enters into action. My own hypothesis is that the path that has most favoured the fertility of the "signal hypothesis" is not the one that has most claimed to be committed to doing so, namely, the sociology of knowledge institutionally recognized as an academic discipline.

\section{1}

The fertility of a seed that floats in the breeze depends on the fertility of the terrain on which it eventually lands. The same can be said, by analogy, of the 
fertility of a hypothesis, whether a signal one or not. I argue that since the seminal writings of Mannheim, our floating seed has 'landed' on at least three distinct 'terrains.' One of them is constituted by Wittgenstein's philosophy of language insofar as this is manifested in Thomas Kuhn's philosophy of science. Another, which I consider the most fertile of all, is constituted by intellectual history and the history of science. In this terrain there is no place for the systematic thought of any author in particular, but only for inspired case studies, one of which especially, published in I97I, rose to a paradigmatic position. I refer to the study by Paul Forman "Weimar culture, causality, and quantum theory, I9I8-I927. Adaptation by German physicists and mathematicians to a hostile intellectual environment." I return to this work in section 3. A third is the multifaceted terrain of sociological thought itself, in which flourished the sociology of knowledge that eventually became established as an academic discipline - this discipline that, from time to time, seems to feel the need to make clear that it remains alive and kicking. This terrain essentially consists of solutions to problems of a metatheoretical nature. This is why I consider it to be the least fertile of the three. There is something particularly curious about it because, of all three, it is the only strand constituted by a body of thought explicitly committed to defining the courses to be taken by the discipline, and yet it is simultaneously the only one where our "signal hypothesis", I would argue, 'germinated' poorly. The writings constituting this variant have been authored by sociologists of the highest renown - we are talking about the likes of Peter Berger and Norbert Elias - and yet they have never managed to rise beyond a merely programmatic level. These are writings that are always reflecting, recommending or problematizing, but never formulating a specific problem or defending a specific thesis that might inspire the formulation of new problems and new research hypotheses. However sophisticated these reflections and recommendations may be from a metatheoretical viewpoint, they turn the discipline into an eternal promise, given that they never succeed in establishing an empirical investigative agenda of the sort achieved by the writings constituting the other two terrains.

Having made these initial remarks, and remembering that whenever our "signal hypothesis" enters into action, a sociology of knowledge - albeit not necessarily the academic discipline known as the sociology of knowledge - begins to live and kick, I am left with the task of showing what befell our "signal hypothesis" in each of the terrains on which it came to land. The following three sections focus on each of these terrains respectively.

\section{2}

The 'fertility' of the first terrain ultimately resides in three theses formulated by Thomas Kuhn in his seminal The structure of scientific revolutions, first published in I962. All of the theses, insofar as they are built on the premise that 
scientific knowledge is ultimately a particular form of language and, as such, has no existence outside the uses made of this same language in specific circumstances, bear the mark of the philosophy of language set out in Wittgenstein's Philosophical Investigations.

The first is enunciated in the final lines of The structure of scientific revolutions: "Scientific knowledge, like language, is intrinsically the common property of a group or else nothing at all. To understand it we shall need to know the special characteristics of the groups that create and use it" (Kuhn, I962: 208). The second can be expressed in the following terms: precisely because it is "the common property of a group," scientific activity presumes far more the socialization in specific paradigms and a disposition for the arid, detailed, dull, mostly unreflective work of the everyday life of the laboratories than any 'rational debate,' given that the latter only emerges in special circumstances. Combined, these two theses converge on the third: scientific knowledge always bears the mark of the worldviews, values, commitments and beliefs shared by the members of the community in which it is produced.

In the introductory section, where I described the successive efforts to redefine the discipline's courses that became characteristic of the sociology of knowledge for at least three decades, I remarked that two of the very few attempts to have proven capable of opening a field of empirical investigation were the Strong programme in the sociology of knowledge and the so-called sociology of scientific knowledge. Here one can add that the reason for this success lies in the fact that these attempts were all descendants of the aforementioned theses of Kuhn. Their source of inspiration was a sociology of knowledge that does not exist as an academic discipline, but even so is alive and kicking within a philosophy of science sculpted in Wittgenstein's philosophy of language. Operating from its intrauterine condition, this sociology of knowledge opened a formidable field of empirical investigation, focused on the ways through which scientists reach agreement on what is considered a scientific fact, a good theory, evidence, an empirical proof, a crucial experiment, a successful experiment, a replication of an experiment, a valid argument, a refutation of a theory, an error and so on. ${ }^{4}$

However, the legacy of this intrauterine sociology is not exhausted here. Kuhn's second thesis described above imparted an additional agenda of investigation: how are decisions taken within the scientific community? How are scientific controversies settled? How does the dogmatic attachment to certain worldviews prove, in some circumstances, to be of fundamental importance to the development of scientific knowledge? In what circumstances does rational debate perform a relevant role in scientific activity?

This agenda has occupied successive generations of sociologists ever since it was posited. Anyone who picks up a volume of the periodicals Social Studies of Science or Science, Technology and Human Values, among others, will soon 
come across some work setting out to discuss at least one of the questions in this investigative agenda. As far as I can tell, the discussions raised by these works converge on a thesis that can be expressed in very simple terms: every form of knowledge, including scientific, is contingent on localized games of interest and agreements. ${ }^{5}$ return to this thesis in the next section for reasons that will become clear. For now, suffice to mention that despite appearing overly generic, the thesis is fertile because it contains another more specific argument: namely that factors of an extra-cognitive kind may be determinant in the rejection of a theory by the scientific community. This thesis was illustrated in exemplary fashion by the historians of science John Farley and Gerald Geison (I974), who sought to show the way in which factors of a political variety helped overthrow the theory of spontaneous generation of Pouchet, the great rival to Pasteur.

Although the thesis highlighted above (in italics) is one of the main pillars both of the Strong programme and the sociology of scientific knowledge, both heavily influenced by the writings of David Bloor, the thesis that Bloor himself seeks to illustrate in his Knowledge and social imagery (the work that constitutes the 'founding landmark' of the Strong programme) is slightly different. The first part of the work is dedicated to a metatheoretical recommendation: a sociology of knowledge worthy of the name must be governed by principles of causality, impartiality, symmetry and reflexivity. In the second, and this is what matters here, Bloor seeks to show what can be achieved if we observe these principles. As far as my understanding goes, we can arrive at a thesis - whose nature is, truth be told, much more epistemological than sociological - that I would summarize in the following terms: every body of knowledge, no matter whether true or false, rational or irrational, produced by an Einstein or by a self-styled flat earther, it is only a body of knowledge because it expresses some socially sanctioned form of operating specific objects and making inferences on this basis. Bloor illustrates this thesis taking mathematical knowledge as an object of discussion. He seeks to show that mathematics, as a body of knowledge, is indissociable from a "characteristically mathematical" mode of grouping, ordering and separating physical objects. ${ }^{6}$ Admittedly, the mere postulation of the existence of a characteristically mathematical mode of behaving is fairly inspiring, but I am unaware whether it actually inspired any noteworthy discussion. I do know, however, of a counterexample. In I992, the sociologist Sal Restivo published a book entitled Mathematics in society and history: sociological inquiries, whose objective was, in the words of Restivo (I992: $\mathrm{X}$ ) himself, "to illustrate different, sociologically grounded, ways of thinking, writing, and speaking about mathematics." I searched in vain for the mark of Bloor and his strong sociology of knowledge in the book. The only time Restivo mentions it is to say that the strong sociology of mathematics present in his book should not be confused with the strong sociology of knowledge proposed by Bloor. 


\section{3}

In the summer of I923, the German physicist Max Born, who would later receive the Nobel Prize for Physics for his work in the development of quantum theory, expressed the feeling that dominated German physicists of the period when he declared that "the entire system of concepts of physics must be rebuilt from the ground up" (Forman, I97I: 6I-62). This declaration had a specific target: the idea, until then considered unassailable, that physics was by its very nature a science committed to the formulation of causal explanations. For a 'sketch' of a sociology of knowledge to emerge in a case like this, all that is necessary is some response, even in essay form, to the following question: what is 'socially explicable' in this refusal of German physicists to commit to causal explanations? More specifically: what relation might a refusal of this kind have to the place and period in which it occurred, namely Germany during the first years of the Weimar Republic? If the response is not essay-like in format, but is based on a systematic empirical investigation, sufficiently well-articulated to inspire successive generations of scholars to study analogous problems and formulate a body of testable hypotheses concerning this same topic and correlate themes, then we are no longer faced with a sketch of a sociology of knowledge, but a sociology of knowledge properly speaking, and one of the highest level.

It was precisely a response of this kind (running to I I5 pages) that the historian of science Paul Forman offered in his article "Weimar culture, causality, and quantum theory, I918-I927," cited above. There is something perturbing about this response: it was formulated without any assistance from the literature produced under the label "sociology of knowledge." The academic discipline with a significant input into his formulation was instead so-called intellectual history, especially the contribution made by the intellectual historian Max Jammer in a book called The conceptual development of quantum mechanics. This response - which incidentally became known as "the Forman thesis" - can be summarized as follows: the urge to reconstruct physics from scratch peculiar to the most eminent German physicists of the first years of the Weimar Republic, especially the urge to construct a physics not bound up with the concept of causality, was a way these same physicists found to adapt to the hostile intellectual climate of the exact sciences more generally, and to the concept of causality in particular, which became established in Germany soon after the country's humiliating defeat in the First World War. Before the end of the war, when Germans found the idea of defeat unimaginable, the intellectual climate was the exact opposite: any science worthy of the name should be capable of offering causal explanations. The same physicists who previous to defeat had displayed pride in the (causal) science they practiced came to see it afterwards as fundamentally outmoded. Defeat generated a widespread feeling of crisis to which even scientific knowledge found itself compelled to adapt or see its reputation tarnished. In this context, a scientific discipline not seen to be "in 
crisis" merited little respect. And since being in crisis became, so to speak, the password to achieving a good public image, both inside and outside the universities, everything that the physicians (and mathematicians) of this period did involve making use of this password. Hence, the eagerness to reconstruct physics "from scratch," without being bound by the concept of causality - an eagerness that, it is important to stress, would prove of fundamental importance to the subsequent development of quantum mechanics. Could there be any better example of a strong sociology of knowledge than the postulate of a thesis like this?

This thesis, it should be pointed out, has been the subject of fierce controversies, yet its controversial nature has not prevented it from prospering. The text has been in existence now for over four decades (what other thesis formulated within the boundaries of the sociology of knowledge itself can display the same?) and throughout this period it has never ceased being a source of inspiration for empirical research. Unsurprisingly, the landmark of four decades did not pass by unacknowledged. The celebration began four years earlier when a large meeting was organized, entitled The cultural alchemy of the exact sciences: revisiting the Forman thesis. A conference at the University of British Columbia. In the opening remarks to this meeting, which took place in March 2007, the speaker (unidentified) remarked that Forman's thesis "permanently changed the disciplinary landscape of the history and philosophy of science" and "contributed just as significantly to the appeal of the new sociology of scientific knowledge."

Acknowledging the pertinence of these remarks, what matters to us here is knowing whether by "permanently chang[ing] the disciplinary landscape of the history and philosophy of science," Forman's thesis also changed in some way the 'disciplinary landscape' of the sociology of knowledge. In the opening remarks cited above, it is said that Forman's thesis "contributed just as significantly to the appeal of the new sociology of scientific knowledge." Unfortunately, the text fails to explain what the 'appeal' is of the "new sociology of scientific knowledge," but the aforementioned book review of Coser can help shed some light. Commenting on a chapter entitled "The conventional component in knowledge and cognition," contributed by Barry Barnes (whose main work is cited in note 5), Coser describes Barnes's argument in the following terms:

Barnes argues that bodies of knowledge are developed in the main because they serve different kinds of interest. All are socially sustained, whether they are rational or not, as component parts of a given culture. A body of knowledge is used because it serves dominant particular interests, not because it is inherently more rational than another (Coser, 1987: 219).

I presume that the appeal of the new sociology of scientific knowledge resides precisely in the above argument. This indeed can be seen as a reverberation of Forman's thesis, although the latter does not authorize the generalization that all bodies of knowledge are "socially sustained as component parts of a given culture." In truth, this generalization is much more a premise in search of an illustration than 
a hypothesis to be tested. And the sociology of scientific knowledge has no shortage of case studies with the objective of illustrating the premise, turned conclusion, that "bodies of knowledge are developed in the main because they serve different kinds of interest [...] whether they are rational or not." Perhaps no other case study better illustrates this premise (turned conclusion) than the one presented by Donald MacKenzie (1978) in his work "Statistical theory and social interests". The focus of this text was a controversy that occurred at the dawn of the twentieth century between two statisticians, Yule and Pearson, concerning the adequacy of their respective statistical association measures, the well-known Yule's Q and Pearson's C. MacKenzie's thesis is that the terms of the objections exchanged between these statisticians are not intelligible in the form in which they are presented since they conceal the interests that drove each of them to formulate their respective objections. Pearson formed part of a small group of statisticians who shared an interest in promoting eugenics; Yule had no affiliation to any specific group and took statistical prediction as an end in itself. Pearson belonged to a rising professional class, which sought to assert its superiority on the basis of the intellectual abilities of its members; Yule belonged to a decadent conservative elite that repelled whatever might appear like eugenics. In the history books on statistics all of this tends to be ignored. For MacKenzie, this is an error, given that, in his view, the objections exchanged between Yule and Pearson are only truly intelligible insofar as they are considered in light of the above information. For example: in one of his attacks on Yule, Pearson argued that the " $\mathrm{Q}$ " coefficient has little predictive power. An observer well versed in statistics, but without knowledge of the sociology of knowledge, would say that Pearson's argument was formulated in "strictly statistical" terms. MacKenzie would respond to this observer that there is no strictly statistical argument and that alleging that Pearson's attack on Yule was strictly statistical loses sight of the fact that this attack expressed an interest that had nothing to do with statistics: namely, the promotion of eugenics by the group of statisticians to which Pearson belonged. Consequently, not even statistical knowledge fails to reflect specific social interests.

An exercise like this, demonstrating the permeability of statistical knowledge to social interests, can indeed be seen as a reverberation of Forman's thesis, but I do not think that this was the kind of exercise that Forman wished to inspire. The exercises that better illustrate Forman's legacy are those that, like his own, seek to offer responses to specific problems. Put otherwise, I believe that the most important legacy of Forman's thesis resides in the characteristics of the field of discussion and empirical investigation that his thesis opened up. This is a field composed not of illustrations of pre-established conclusions, nor of recommendations of a metatheoretical kind such as those I shall demonstrate in the next section, but of responses to substantive questions like those implied in the titles ${ }^{7}$ of some of the works presented at the meeting to which I referred 
earlier (27 in total), which were later edited into a collection by Carson, Kojevnikov and Trischler (20I I) under the title Weimar culture and quantum mechanics. The Forman thesis: 40 years after.

Unfortunately, given the limits of an article, I am unable to discuss the sociology of knowledge that is alive and kicking in the works listed in note 7. Since the path that led to all these works was opened up by the sociology of knowledge that pulsates within Forman's thesis, however, I can seek to demonstrate what is special about this sociology of knowledge. Its basic ingredient has already been mentioned: the formulation of a substantive problem, namely explaining the emergence of the feeling, widespread among the German physicists of the first years of the Weimar Republic, that physics should renounce its traditional commitment to the formulation of causal explanations. The remaining ingredients are of two types: those that led to the formulation of this problem and those that related to the attempt to offer a response.

The ingredients that led to the formulation of this problem were the interlocution with the contributions of "intellectual history" concerning the conceptual development of quantum mechanics and the identification of a paradox: the place (Germany) and the period (I9I8-I927) displaying the deepest hostility to physics and mathematics was also one of the most creative throughout the entire history of these disciplines. Notably, a sketch of a sociology of knowledge is already present in the very postulate that we are faced by a paradox, given that outside the frameworks of a sociology of knowledge there was nothing paradoxical in what was being described. The argument would be simply that science is autonomous in relation to its social environment, it develops or evolves according to its own laws and thus there is nothing paradoxical about a scientific discipline developing in an environment hostile to it. The mere possibility of an argument of this kind becoming enunciated already forces Forman to formulate an alternative hypothesis that may prove more sustainable. The alternative hypothesis that Forman arrived at was as follows:

We may suppose that when scientists and their enterprise are enjoying high prestige in their immediate (or otherwise most important) social environment, they are also relatively free to ignore the specific doctrines, sympathies, and antipathies which constitute the corresponding intellectual milieu. With approbation assured, they are free of external pressure, free to follow the internal pressure of the discipline which usually means free to hold fast to traditional ideology and conceptual predispositions. When, however, scientists and their enterprise are experiencing a loss of prestige, they are impelled to take measures to counter that decline (Forman, I97I: 6).

At first glance, this hypothesis may appear a mere 'glimmer' of a sociology of knowledge, but it is actually much more than this. Glimmers appear in essay-like works, such as the renowned text by Mannheim (I953) "Conservative thought." There is no ignoring the brilliance of Mannheim's writing in this es- 
say, but he does not formulate specific hypotheses capable of opening up an agenda of empirical investigation to be explored in the future. With Forman's thesis, by contrast, we are presented with a specific hypothesis, which, like any hypothesis worthy of the name, can be tested, proven true or false, and inspire the formulation of other hypotheses. It was Forman's attempt to demonstrate the validity of this hypothesis that led him to the idea that the almost unparalleled development experienced by physics and mathematics during the period studied by him was not due to the "internal dynamics" of science, as typically alleged, but to the fact that the physicists and mathematicians active during the period in question had felt threatened by an environment hostile to their respective disciplines and, as a consequence, compelled to refound them in order for them to enjoy a good public image. The legacy of this thesis translates into a question, addressed by successive generations of scholars, which can be expressed as follows: does a relation exist between scientific development and the task that occasionally compels scientists to adapt to a hostile environment? Three decades of attempts to define the direction taken by the sociology of knowledge did not lead to a single problem capable of mobilizing successive generations of scholars in the way that the Forman thesis did.

\section{4}

The moment has arrived to discuss what happened to our "signal hypothesis" on the terrain on which the sociology of knowledge flourished as an academic discipline. I begin by recalling that there were many attempts to redefine the course taken by this discipline but ultimately none of them prospered with the exception of the strong sociology of knowledge and the sociology of scientific knowledge, precisely those derived from a sociology of knowledge that does not exist as an academic discipline, but that, working from its intrauterine condition (as we saw in section 2), succeeded in opening up a rich field of empirical investigation.

In the chapter that Merton devoted to the sociology of knowledge in his famous Social theory and social structure, cited earlier, he attributed the task of systemizing the knowledge thus far (in the I940s) produced in this discipline. To this end, he proposed to develop what he himself called a paradigm for the sociology of knowledge through which it be possible to produce

an inventory of extant findings in the field; for indicating contradictory, contrary and consistent results; setting forth the conceptual apparatus [...] in use; determining the nature of problems which have occupied workers in this field; assessing the character of the evidence which they have brought to bear upon these problems; ferreting out the characteristic lacunae and weaknesses in current types of interpretation (Merton, 1968: 557).

In formulating this proposal, Merton (I968: 557) expected that as the years passed, the flaws contained in it could be gradually corrected until "an 
improved and more exacting analytical model" took hold. But the years passed and this analytic model never appeared. What was witnessed thereafter was, as I mentioned earlier, a frenetic succession of attempts to refound the discipline: first, that of Berger and Luckmann (I966), who ignored the existence of the paradigm proposed by Merton; next, that of Norbert Elias (I97 Ia, b), who ignored both Merton's paradigm and the effort of Berger and Luckmann; afterwards, that of David Bloor (I976), which, as we saw, prospered without any help from the sociology of knowledge as an academic discipline; next, the self-denominated new, hermeneutically grounded sociology of knowledge, which ignored all the previous attempts; and, to conclude, the proposal to found, in the wake of the attempt to define a new direction made by Berger and Luckmann, a hermeneutic sociology of knowledge, which, curiously, maintained no relation to the new, hermeneutically grounded sociology of knowledge.

It is not difficult to understand this succession of disparagements: if different proposals follow one another without being aware of the other's existence, this is because none of them formulates a specific problem, nor, much less, offers any kind of solution in the way Forman's thesis did. Instead of specific problems, they offer: a) reflections on the conditions of possibility of the sociology of knowledge itself, on the metatheoretical dilemmas that supposedly plague the discipline and on the nature of the knowledge that this discipline can produce; b) recommendations on how to establish, within the discipline, a "unified theoretical-conceptual" framework that can serve as a guide for empirical investigation; and c) the problematization of certain conceptions deep-rooted in the discipline. Let's examine each item in turn.

The best way to clarify what is meant in item " $a$ " is to present examples of the reflections to which I refer. I begin with one concerning the metatheoretical dilemmas that supposedly haunt the discipline:

Social and cultural theories that seek robust explanations of practices face a recurrent dilemma: how to reconcile agents' capacities with inevitable social limitations upon them; or, to put it more generally, practical agency with cultural constraint. These persistent dilemmas are perhaps most apparent in two areas of social inquiry: theories of action and the sociology of knowledge (Bohman, I997: I7I).

According to this excerpt, the very viability of the sociology of knowledge as a body of knowledge appears to depend, at least partially, on the offer of a good solution to the dilemma of how to "reconcile agents' capacities with inevitable social limitations." It may be that the number of solutions offered by this dilemma in sociological thought have already reached two figures. Whatever the case, there are other dilemmas, supposedly related to the viability of the discipline, for which some solution is sought. I have selected one that was posited in the context of the aforementioned new, hermeneutically grounded sociology of knowledge (not to be confused with the hermeneutic sociology of 
knowledge!). It runs as follows: at the same time as the sociologist of knowledge contends that the knowledge produced by him about the knowledge of others is valid independently of the contexts of meaning in which his or her own knowledge is produced, he or she is also "confronted with context of meanings in which agents themselves make assumptions about the truth and validity of their beliefs and statements." It is necessary to distinguish, therefore, between two sets of validity-imputations: that of the sociologist, which is supposedly scientific-theoretical and that of the agent, which is lifeworldly-contextual. Hence, the big problem: how do "these two sets of validity-imputations, the scientific-theoretical and the life worldly-contextual, relate to each other?" How, in other words, does "the sociologist relate to the interpretive schemes of agents in the lifeworld while also being in a situated position?" (Kögler, I997a, p. I59).

It is difficult to imagine any attempt more innocuous than that of seeking to offer a solution to problems like those described above. In relation to the former, let us admit that the described dilemma actually exists and that it is even persistent. My question then is: what difference does this make? What harm does the persistence of this dilemma cause to the sociology of the knowledge in terms of its capacity to establish agendas for empirical investigation and explanations for specific phenomena? If the reply is "none," "I don't know" or silence, the postulated dilemma is irrelevant and, consequently, the exercise of describing it and searching for a solution is, I venture to say, futile. Among the options suggested, my own wavers between "none" and "I don't know," but the response of those who, under the pretext of reflecting on the conditions that need to be met for sociology to produce valid knowledge about itself and about other forms of knowledge, set out to describe the persistent dilemmas that supposedly hinder the production of this knowledge tends to be a resounding silence. In relation to the second problem mentioned, we can apply the same reasoning: what are the phenomena not being adequately explained because of the lack of a solution to this problem of, we could say, elucidating the relationship between the two cited "sets of imputations of validity"? None? Nobody knows? Once again, we are faced with the search for a solution to a problem that, if it indeed exists, requires no solution. That suffices for item "a." We can turn, then, to item "b," which concerns the recommendations of a metatheoretical nature that became characteristics of the discipline.

With regard to this item, I think it would be difficult to encounter so many recommendations in such little space as in the abstract written by Norbert Elias for his article "Sociology of knowledge: new perspectives," originally published in I97I:

The core problems of sociological and philosophical theories of knowledge remain insoluble and unrelated as long as both theories start from static models. The problems can be solved, and the respective theories related to each other, without undue difficulties if the acquisition of knowledge is conceptualized as a longterm 
process which takes place within societies also considered as long-term processes. This approach has the added advantage of being in closer agreement with the evidence. The paper indicates what needs to be unlearned and what to be learned in order to prepare the way for such a unified theoretical framework which can serve as a guide to, and which can be in turn corrected by, empirical sociological studies of all types of knowledge, scientific and practical as well as non-scientific or ideological (Elias, I97ıa: I49).

As we can see, Elias (I97Ia: I49) was striving to "prepare the way" for the formulation of a "unified theoretical framework" able to "serve as a guide to [...] empirical sociological studies of all types of knowledge." More than 45 years later, no sign exists of this "unified theoretical framework." Why was it never formulated? Simply because this is an offer without a demand, just like the solutions offered for the dilemmas and problems described previously. What exactly is the specific problem that cannot be solved unless the sociology of knowledge becomes provided with a unified theoretical framework? Elias does not answer, simply because there is nothing to answer. A unified theoretical framework is not something planned, it is something done, perhaps without even perceiving that it is being done, when seeking a solution to a specific problem. An example? Freud and his unified theoretical framework, psychoanalysis. Was there some problem demanding this framework? There was: explaining how, for example, someone could suffer from numbness in one arm, as happened to one of its patients, if nothing explained the occurrence of a symptom of this kind from a clinical point of view. Unable to offer up a similar kind of problem, though, Elias presented the recommendations that appear from the first to final line of his abstract. Granted, the recommendations are good, but recommendations that do not respond to any kind of specific demand tend to eventually vanish without trace.

Curiously, just five years before Elias pointed towards a unified theoretical framework, Peter Berger and Thomas Luckmann, no less, did the very same. Following in the trail of Talcott Parsons's thought, their stated aim was to produce "a single body of systematic theoretical reasoning" so as to elucidate "the full theoretical significance of the sociology of knowledge." Fifty years later, has any such thing been elucidated? No! And why not? Simply because the proposed elucidation is another offer without a demand. As in the case of Elias's unified theoretical framework, the single body of systematic theoretical reasoning of Berger and Luckmann is not constructed on the basis of some substantive problem, but recommendations of a metatheoretical nature, as in the following:

the sociology of knowledge must concern itself with whatever passes for "knowledge" in a society, regardless of the ultimate validity or invalidity (by whatever criteria) of such "knowledge." And in so far as all human "knowledge" is developed, transmitted and maintained in social situations, the sociology of knowledge must seek to understand the processes by which this is done in such 
a way that a taken-for-granted "reality" congeals for the man in the street. In other words, we contend "that the sociology of knowledge is concerned with the analysis of the social construction of reality" (Berger \& Luckman, I966: I4, original italics).

The exhortations are clear: "the sociology of knowledge must concern itself with whatever..." or: "the sociology of knowledge must seek..." But why do the authors themselves not concern themselves or seek rather than appealing to others to do so? The answer is simple: because, just like Elias, they believed that a unified theoretical framework would be necessary to serve as a guide for future empirical studies, and their own task was solely to produce this framework. Unsurprisingly, this project was never realized, although it led to a veritable avalanche of recommendations of a metatheoretical nature. The aforementioned proposal for a hermeneutic sociology of knowledge (not to be confused with the new, hermeneutically grounded sociology of knowledge, proposed two years earlier!), which announces its debt to the work of Berger and Luckmann, is above all an expression of this kind of avalanche. Its discussion agenda is composed of recommendations on every subject imaginable: from how to overcome the "intentionalistic reductionism of understanding that is satisfied with a reconstruction of actors' subjective perspectives" to how "to elucidate the objective conditions under which sense configurations can occur in everyday life," and including recommendations on how to avoid both the "normativization" and the "subjectivization" of the sociology of knowledge (Schnetler, 2002). Indeed, "overcome," "elucidate" and "avoid" appear to be the keywords of the sociology of knowledge practiced recently in some circles.

Nevertheless, few ideas are more widespread in sociological thought than the notion of social construction. This expression seems to have seduced everyone from an author more than deservedly renowned like Mark Granovetter, who more than ten years ago published an article called "The social construction of corruption" (Granovetter, 2006), to some starting their career like the promising anthropologist Joana Ramalho Ortigão Corrêa, who recently published the article "The social construction of fandango as a popular cultural expression and a theme in folklore studies" (Corrêa, 20I6). The fact is, though, that such works owe absolutely nothing to the recommendations of Berger and Luckmann. What the latter call an analysis of the social construction of reality can only be pursued in light of the unified theoretical framework that they themselves propose to develop - and for this same reason, they could not bequeath the sociology of knowledge an agenda of empirical investigation, but merely recommendations and reflections of a metatheoretical kind, notably those articulated around the verb "elucidate."

At the level relating to item "c," the "problematization" of conceptions deep-rooted in the discipline, the sociology of scientific knowledge seems to have been more successful. It has to be acknowledged, as Michel Mulkay (I979) aptly showed, for example, that sociological thought sometimes incorporates 
acritically some equivocal conceptions concerning the range and validity of scientific knowledge. One of them is that scientific knowledge is, by its very nature, indispensable for the spectacular discoveries that surround us, whether in the field of science itself, such as the case of vaccines, or in the field of technology, examples of which I leave to the reader's imagination. This idea presumes that scientific development always precedes, and is necessarily indispensable to, technological development. Many academic disciplines very rightly problematize this idea, and the sociology of scientific knowledge is no exception. An exercise of this nature can, without doubt, establish a rich agenda of empirical investigation. The very scientific basis of the discovery of certain vaccines would be a good theme to investigate. Pasteur, for example, credited with discovering the rabies vaccine, had very little scientific knowledge about how a vaccine acts once inoculated in the human organism. As late as the I880s, he presumed that immunity resulted from the exhaustion of the essential nutrients required by the bacteria to thrive in the host organism. This idea, known as the depletion theory, would prove bizarre just a few years later. Likewise, the German bacteriologist Robert Koch, seen as responsible for the discovery of the tuberculosis vaccine, also had little scientific knowledge about how the vaccine worked. Around I890, he noted the presence of the anthrax bacillus in the leukocytes of sick animals and concluded, much to the scorn of future generations, that the leukocyte was the medium through which the bacteria enters the body, multiplies and then spreads to different organs. ${ }^{8}$ These bizarre errors of judgment committed by major scientists point to a clear mismatch between the intrinsic validity of scientific knowledge and the utility of scientific practice. A practice (a vaccination, for example) based on knowledge later revealed to be invalid from a scientific viewpoint (such as the knowledge embedded in the aforementioned depletion theory) may prove more useful than a practice based on knowledge whose scientific validity is unquestioned. In fact, this observation is not in the least surprising for specialists from the area. An immunologist once explained to me in a personal communication that the discovery of the diphtheria vaccine had been very good for humanity but very bad for immunology itself as a scientific body of knowledge, since the vaccine's success had diverted attention from more promising lines of research. I have no way of knowing if this is true, but it is a marvellous illustration of the mismatch I have in mind: in this specific case, the usefulness of the knowledge of immunology conspired against the progress of this same body of knowledge. It has to be admitted that one need not be a leading historian of science nor be called Paul Forman to convert a mismatch of this kind into an object of sociological investigation, but it helps greatly not to become lost in futile reflections - whether on the nature of the knowledge produced by the sociology of knowledge, or on the conditions of possibility of the production of this knowledge - nor in equally futile recommendations about how to overcome supposed metatheoretical 
dilemmas or elucidate the theoretical meaning of conceptions supposedly central to the discipline, or avoid the adoption of reductionist analytic approaches. Reflections and recommendations of this kind are only justified when confronting a challenge like the one cited above demands. In the absence of an empirical problem whose solution requires these kinds of reflections, recommendations and problematizations, the latter are merely a good theme for classroom discussion, school exams and publishing articles. Nothing else.

\section{5}

By way of conclusion, I would like to re-emphasize that the sociology of knowledge can exist as an academic discipline and as a body of knowledge. There is no discipline without the body of knowledge, but there can be a body of knowledge without the discipline. Paraphrasing the title given by Coser to the book review cited in the first paragraph of this article, I would say that the sociology of knowledge, as a body of knowledge, can be alive and kicking both in the state of an academic discipline, more precisely the discipline we know by the name of sociology of knowledge, and in the state I have called here intrauterine. In this case, it only exists insofar as it pulsates within other disciplines, such as the philosophy of science, the history of science and intellectual history. The thesis defended here is that while this intrauterine sociology of knowledge kicks by offering explanations for specific phenomena, the other, the one constituted as an academic discipline, kicks by reflecting on the conditions of possibility of the production of knowledge about knowledge itself, about the nature of the knowledge produced in these conditions, on the metatheoretical dilemmas that supposedly plague the production of this knowledge, on the means of overcoming these dilemmas, on the conceptual problems supposedly involved in the production of this knowledge and on the ways of solving these conceptual problems. Certainly, it is not due to a lack of reflection on its own capacity to produce knowledge about knowledge that this sociology of knowledge will cease to prosper.

Received on 24/IO/20I8 | Revised on 29/4/2019 | Approved on 31/5/2019

Renan Springer de Freitas is professor of sociology at UFMG. Author of Sociologia do conhecimento, pragmatismo e pensamento evolutivo (2003), Judaísmo, racionalismo e teologia cristã da superação: um diálogo com Max Weber (2010), and Ciladas no caminho do conhecimento sociológico (2020). Member of the Editorial Board of the journal Philosophy of the Social Sciences. 


\section{NOTES}

I See in particular Kögler (I997a, b) and Burkitt (I997).

2 Especially following the publication of Das Problem einer Soziologie des Wissensin I924 and Ideologie und Utopie in I929.

3 "The sociology of knowledge came into being with the signal hypothesis that even truths were to be held socially accountable, were to be related to the historical society in which they emerged" (Merton, I968: 514).

4 Among the works that worked around this focal point in particular, aside from the work by Bloor (I976), already cited, we can highlight the texts of Latour and Woolgar (I979), Knorr-Cetina (I98I) and Collins (I985).

5 See, especially, Barnes (I977).

6 See, especially, Chapter 5 of the book by Bloor cited above. I engaged in this discussion myself in Freitas (2004).

7 Some of these titles (with the names of the authors afterwards in brackets) are: "Philosophical rhetoric in early quantum mechanics I925-I927: high principles, cultural values and professional anxieties" (Alexei Kojevnikov), “"The shackles of causality': physics and philosophy in the Netherlands in the interwar period" (Kai Eigner \& Frans van Lunteren), "Crisis, measurement problems and controversy in early quantum electrodynamics: the failed appropriation of epistemology in the second quantum generation" (Anja Skaar Jacobsen), "Weimar culture and quantum mechanics science and politics: pathology in Weimar Germany (I9I8-I933)" (Cay-Rüdiger Prüll), "Jordan alias Domeier: science and cultural politics in late Weimar conservatism" (Richard H. Beyler), "The causality debates of the interwar years and their preconditions: revisiting the Forman thesis from a broader perspective" (Michael Stöltzner), and "Modern or anti-modern science? Weimar culture, natural science and the Heidegger-Heisenberg exchange" (Cathryn Carson).

8 On this point, see Tauber (I990). 


\section{BIBLIOGRAPHY}

Barnes, Barry. (1977). Interests and the growth of knowledge. London: Routledge.

Berger, Peter \& Luckmann, Thomas. (I966). The social construction of reality: a treatise in the sociology of knowledge. New York: Penguin Books.

Bloor, David. (1976). Strong programme in the sociology of knowledge. In: Knowledge and social imagery. Chicago: The University of Chicago Press.

Bohman, James. (1997). Reflexivity, agency and constraint: the paradoxes of Bourdieu's sociology of knowledge. Social Epistemology, II/2, p. I7I-I86.

Burkitt, Ian. (I997). The situated social scientist: reflexivity and perspective in the sociology of knowledge. Social Epistemology, II/2, p. I93-202.

Carson, Cathryn; Kojenivkov, Alexei \& Trischler, Helmuth (eds.). (20II). Weimar culture and quantum mechanics. The Forman thesis: 40 years after. London: Imperial College Press.

Collins, Harry. (1985). Changing order: replication and induction in scientific practice. London: Sage.

Corrêa, Joana Ramalho Ortigão. (20I6). A construção social do fandango como expressão cultural popular e tema de estudos de folclore. Sociologia \& Antropologia, 6/2, p. 407445 .

Coser, Lewis. (1987). The sociology of knowledge is alive and kicking. Contemporary Sociology, I6/2, p. 218-220.

Elias, Norbert. (I97Ia). Sociology of knowledge: new perspectives - Part One. Sociology, 5/2, p. I49-I68.

Elias, Norbert. (I97Ib). Sociology of knowledge: new perspectives - Part Two. Sociology, 5/3, p. 355-370.

Farley, John \& Geison, Gerald. (1974). Science, politics and spontaneous generation in nineteenth century France: the Pasteur-Pouchet debate. Bulletin of the History of Medicine, 48, p. I6I-I98.

Forman, Paul. (I97I). Weimar culture, causality, and quantum theory, I9I8-I927. Adaptation by German physicists and mathematicians to a hostile intellectual environment. Historical Studies in the Physical Sciences, 3, p. I-II5. 
Freitas, Renan Springer de. (2004). A saga do ideal de boa ciência. Revista Brasileira de Ciências Sociais, I9/55, p. 9I-I05. Granovetter, Mark. (2006). A construção social da corrupção. Política e Sociedade, 9, p. II-37.

Hitzler, Ronald; Reichertz, Jo \& Schröer, Norbert (eds.). (I999). Hermeneutische Wissenssoziologie. Standpunkte zur Theorie der Interpretation [Hermeneutic sociology of knowledge. Aspects of a theory of interpretation]. (Series: Theorie und Methode, v. I). Konstanz: Universitätsverlag Konstanz.

Knorr-Cetina, Karin. (I98I). The manufacture of knowledge: toward a constructivist and contextual theory of science. Oxford: Pergamon.

Kögler, Hans-Herbert. (I997a). Alienation as epistemological sources: reflexivity and social background after Mannheim and Bourdieu. Social Epistemology, II/2, p. I4II64.

Kögler, H. Herbert. (I997b). Reconceptualizing reflexive sociology: a reply. Social Epistemology, II/2, p. 223-250.

Kuhn, Thomas. (I962). The structure of scientific revolutions. Chicago: The University of Chicago Press.

Latour, Bruno \& Woolgar, Steve. (1979). Laboratory life: the social construction of scientific facts. London: Sage.

MacKenzie, Donald. (1978). Statistical theory and social interests: a case study. Social Studies of Science, 8, p. 35-83.

Mannheim, Karl. (1953). Conservative thought. In: Kecskemeti, Paul (ed.). Essays on sociology and social psychology by Karl Mannheim. London: Routledge.

Merton, Robert. (I968). Social theory and social structure. New York: The Free Press.

Mulkay, Michel. (1979). Knowledge and utility: implications for the sociology of knowledge. Social Studies of Science, 9/I, p. 63-80.

Restivo, Sal. (1992). Mathematics in society and history: sociological inquiries. Dordrecht: Kluwer Academic Publishers. Schnettler, Bernt. (2002). Social constructivism, hermeneutics, and the sociology of knowledge. Forum Qualitative Social Research, 3/4. Available at: <http://www.qualitative- 
research.net/index.php/fqs/article/view/785/I704>. Accessed Mar. I7, 2018.

Stehr, Nico \& Meja, Volker (eds.). (1984). Society and knowledge: contemporary perspectives on the sociology of knowledge. New Brunswick: Transaction Books.

Tauber, Alfred. (I990). Metchinikoff, the modern immunologist. Journal of Leukocyte Biology, 47, p. 56I-567. 
Palavras-chave

Sociologia do conhecimento;

história da ciência;

filosofia da ciência; conhecimento científico;

história intelectual.

\section{A SOCIOLOGIA DO CONHECIMENTO E SEUS MOVIMENTOS}

\section{Resumo}

A sociologia do conhecimento que se constituiu enquanto disciplina acadêmica "vive" lado a lado com outra que não o fez, mas, não obstante, se manifesta no interior de algumas disciplinas, tais como a filosofia da ciência, a história da ciência e a história intelectual. Nesse trabalho discuto o modo como cada uma delas tem-se movido. Argumento que enquanto a primeira se move refletindo sobre as condições de possibilidade da produção de conhecimento acerca do próprio conhecimento, sobre a natureza do conhecimento que se produz nessas condições, sobre os dilemas metateóricos que supostamente atormentam a produção desse conhecimento, sobre os meios de superar esses dilemas, sobre os problemas conceituais talvez envolvidos na produção desse conhecimento e sobre os modos de solucionar esses problemas conceituais, a segunda se move oferecendo solução para problemas empíricos específicos.

\section{THE SOCIOLOGY OF KNOWLEDGE AND ITS MOVEMENTS}

Keywords

Sociology of knowledge; history of science; philosophy of science; scientific knowledge; intellectual history.

\section{Abstract}

The sociology of knowledge that became established as an academic discipline 'lives' alongside another that never did so, but nevertheless manifests itself within other disciplines, including the philosophy of science, the history of science, and intellectual history. I discuss the ways in which each of them has evolved. I argue that while the former works by reflecting on the conditions of possibility of the production of knowledge about knowledge itself, the nature of the knowledge produced under these conditions, the metatheoretical 'dilemmas' that supposedly plague the production of this knowledge, the means by which these dilemmas can be 'overcome,' the conceptual problems supposedly involved in the production of this knowledge, and the ways through which these conceptual problems can be solved, the latter works by offering solutions to specific empirical problems. 